\title{
Evaluation of Drought Hazard Area of GharehAghaj Basin in Iran, Using GIS
}

\author{
Abdol Rassoul Zareiee ${ }^{1}$, Masoud Masoudi2 \\ ${ }^{1}$ College of Agricultural and Natural Science, Fasa University, Fasa, Iran \\ ${ }^{2}$ Department of Desert Zones Management, Agricultural College, Shiraz University, Shiraz, Iran \\ Email: ${ }^{*}$ Ar Zareiee@Yahoo.Com
}

Received 12 October 2013; revised 12 November 2013; accepted 19 November 2013

Copyright @ 2014 by authors and Scientific Research Publishing Inc.

This work is licensed under the Creative Commons Attribution International License (CC BY).

http://creativecommons.org/licenses/by/4.0/

(c) (i) Open Access

\begin{abstract}
In GharehAghaj basin drought has the most profound effect on the way of living and regional economy. Drought Hazard by nature is a result of interrelated parameters concerned. The objective of this paper presents a model to assess hazard of drought using the Geographical Information System (GIS). The data analyzed have been gathered from the records, reports and maps published by the governmental offices of Iran. Various drought hazard indicators have different severity classification in different models. The drought hazard indicator maps take into account the meteorological, hydrological, physical and socioeconomic characteristics that related to drought hazard. Each of the hazard indicator maps and also final hazard map are classified into 4 hazard classes of drought: mild, moderate, severe and very severe. The final hazard classes were defined on the basis of hazard scores arrived at by assigning the appropriate attributes to the indicators and the final hazard map was prepared by overlaying different hazard indicator maps in the GIS, deploying the new model. The final Hazard Map shows that moderate hazard areas $(89.87 \%$ of the basin) are much widespread than areas under severe hazard (10.13\% of the basin) which are observed in the Southeast of the region.
\end{abstract}

\section{Keywords}

Evaluation; Drought Hazard Area; GIS; GharehAghaj Basin; Iran

\section{Introduction}

Drought risk area, by nature, is a result of a variety of factors. Drought in general originates from less precipitation over an extended period of time. These include occurrence of no rain in the rainy season, number and

"Corresponding author. 
amount of rainfall event and other climatic anomalies. Ahmadi used such a method has been conventionally used for preparing the hazard and risk maps for different types of land degradation [1] [2]. In an operational definition of drought it identifies drought from impact data (i.e. crop damage). It is widely accepted that combination of physical nature of area, amount of rainfall and water resource development leads to identify the drought pattern. The shortage of the rainfall, the erratic distribution of the rainfall, highs evapotranspiration, water erosion, low water holding capacity of soil that all of them are the major causes of drought. Anukularmpai applied gamma distribution to predict minimum monthly rainfall in Thailand [3].

Department of Environmental Planning and Policy established the drought risk areas in the northeast using GIS for spatial overlay of variable layers: rainfall index, soil water holding capacity, irrigated area, ground water yield, rainfall probability and land use [4]. Feiznia et al. and Grunblatt et al. reported the frequency rainfall occurrence in the northeast and mapped along with a measure of their variability [5] [6]. Koonthanakulwong concluded the drought on the basis of the number of days with rainfall was less than specified threshold [7].

Masoudiand Kumar assessment the hazard of ground water resource degradation using GIS in Mond Miyani basin, Iran he used five indicator to this study [8] [9].The eighth National Economic and Social Development Plan called for achievement of water resource sustainability [10]. Palmer identified monthly index values for past dry periods to yield an equation for calculating drought severity in four classes [11]. Singh et al. used similar method for assessment Desertification map in Western Rajasthan [12]. Another study of rainfall in the northeast of Thailand made by Siripon and Mongkolsawat concludes that the unevenly distributed rainfall during the rainy season is found extensively and extends longer period in the southwest and the central part of the region [13].

Result of this research shown that severe and moderate hazardous areas it is concluded that the areas under severe hazard cover about $13 \%$ of the total plains, while those under moderate hazard have a greater spread (70\%). Zareiee has shown that moderate hazard areas (63\% of the basin) are much widespread than areas under severe hazard (37\% of the basin) of this region but they used only meteorological indicator [14]. Zehtabian and Jafari used similar factor for evaluation of water resources degradation in Kashan area, but have emphasis on desertification model [15].

This phenomenon is frequently occurred in second half of June and of September for the areas in southwest and northeast of the region respectively. The information obtained from limited studies still requires a more detail identification of spatial pattern of drought. This is to support the government in allocating water for rural consumption more accurately and at the right place. Computer-based analysis and GIS can addresses this issue with higher accuracy, based on the integration of meteorological, hydrological, physical, socioeconomic data of the areas. The purpose of this study is to model drought hazard area using GIS with a set of data layers empirically evaluated.

\section{Material and Methods}

\subsection{Study Region}

GharehAghaj watershed, is one of the main watersheds in Fars province in southwest of Iran. Ghareh Aghaj borders on the Sepidan in the north and the Hormozgan province in the south and Boshehr province in the west and kazeron in the east. This region covers about one-ninth of the total area of the province. Area of this region is $1,264,900$ hectare. It lies between Latitude $28^{\circ} 22^{\prime} 11^{\prime \prime} \mathrm{N}$ and $29^{\circ} 55^{\prime} 23^{\prime \prime} \mathrm{N}$ and Longitude $51^{\circ} 48^{\prime} 15^{\prime \prime} \mathrm{E}$ and $54^{\circ} 24^{\prime} 43^{\prime \prime E ~(F i g u r e ~ 1) . ~ M e a n ~ a n n u a l ~ r a i n f a l l ~ i s ~ a b o u t ~} 320.54$ (mm/annual) that main period of precipitation is during winter ( $60 \%$ of total rainfall). Mean annual temperature is 18.2 centigrade. The climate in most part of the basin is arid and semi arid. Total length of rivers in this basin is over than $360 \mathrm{~km}$ and average of drainage density in this basin is $300 \mathrm{~m} / \mathrm{km}^{2}$. GharehAghaj watershed contains one-sixth of the total population of the Fars province (about $1.3 \times 106$ in 2010). Over $60 \%$ of the population is engaged in agriculture which dominated by irrigated cultivation and secondary stage by dry cultivation production. At the present time, less than $10 \%$ of the cultivated land in the ranges is dry cultivation. In addition, water shortage for domestic consumption is usually identified as principal constraint for the people during the dry season. Lack of the water or drought in the region has profound impact that can be listed as economic, social and environmental (Figure 1).

\subsection{Methodology}

The data obtained were of two types 1) numerical data and 2) thematic maps, but mainly in the map format useful for the GIS analysis. All such relevant data were obtained from the local and main offices and institutes of 


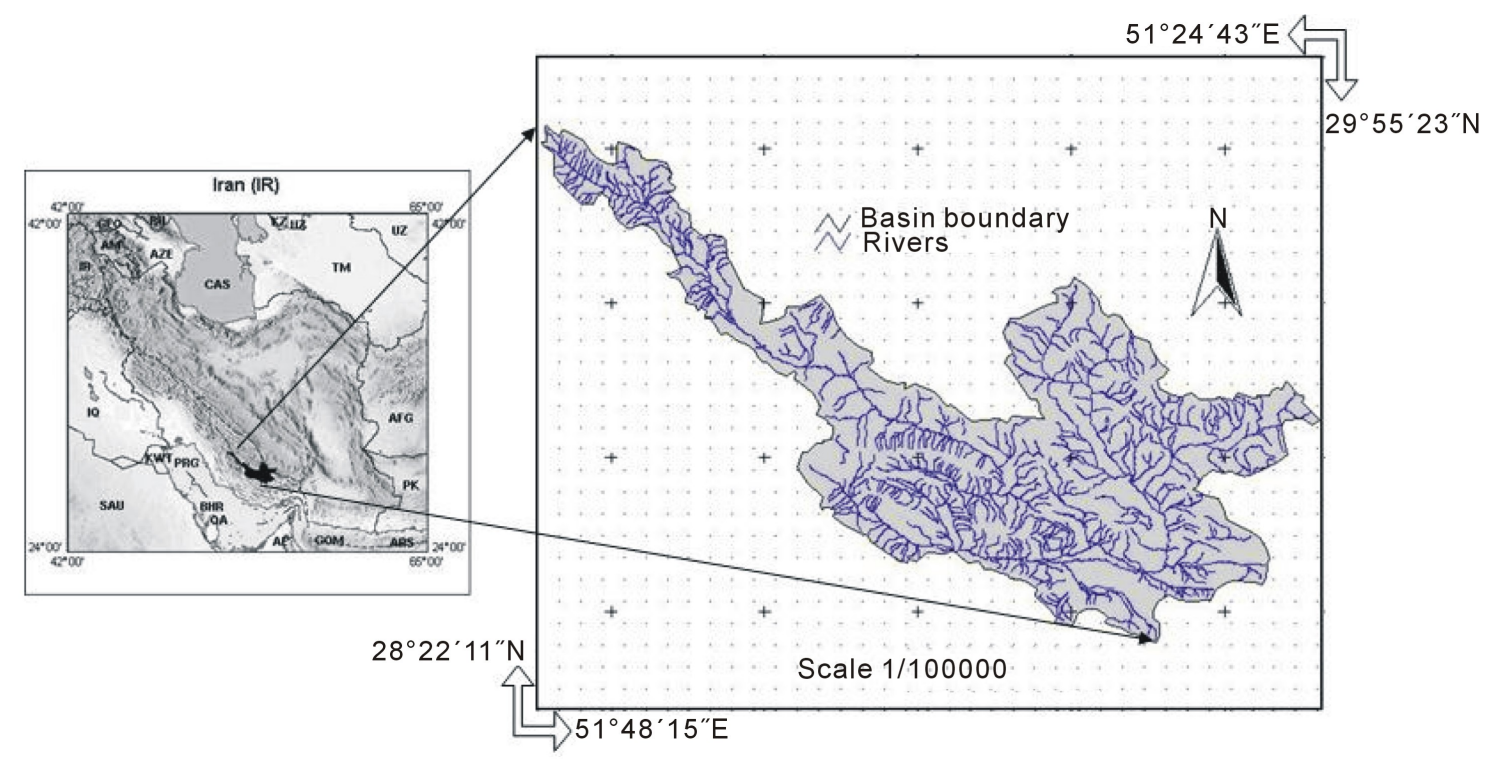

Figure 1. Location of study area and monitoring sections.

the Ministries of Agriculture and Energy and Organizations of Management \& Planning and Meteorology of Iran and processed thoroughly, using the GIS technique (Software of ArcGIS 9.3).

The assessment of the hazard of drought has been attempted by first identifying the main indicators of drought hazard in the study area and then establishing the thresholds (class limits) of severity for indicators and in the end analyzing the hazard. The recommendations appearing in some literature (like Masoudi et al. 2007) as well as the statistically suitable parameters of local conditions like average and standard deviation for some indicators have also been taken into consideration while fixing the thresholds of the five classes of severity (ratings scores between 1 to 4 ) for each indicator. The following twenty one indicators (Table 1) have been processed in the GIS to arrive at the hazard map for each indicator. The indicators are related to meteorological drought, hydrological drought, physical drought and socioeconomic drought.

In order that the effect of all the indicators gets projected in the hazard map, the overlays of the individual hazard maps, derived from eighteen indicators, were analyzed step by step. The severity of hazard assigned to each polygon has been assessed by summing all the attributes (rating scores) of indicators used in the GIS. Such a method has been conventionally used for preparing the hazard and risk maps for different types of drought [1]-[3] [5] [6] [8] [12] [15]. The following equations were used step by step for this map in GIS model:

Hazard score for meteorological drought $=[($ Climate Score $)+($ Annual rainfall Score $)+($ Climate Change Score $)+(1.5 \times$ Coefficient variation Score $)+(1.5 \times$ ratio of vernal arid seasons Score $)+(2 \times$ ratio of arid years Score $)+(2 \times$ Drought Hazard Score $)] / 10$

Hazard score for hydrological drought $=[($ Over exploitation of plans Score $)+($ Hydrogeology of plains Score) + (Stream density in each hydrogeological unit Score) + (Annual average decrease of water Table in each plan Score)] $/ 4$

Hazard score for physical drought $=[($ Derange condition of soil Score $)+($ Slop Score $)+($ Ratio of dry cultivation area to irrigation area in each plan Score) + (Water dependency per capita to irrigated area Score $)+(1.5$ $\times$ Land use Score) $] / 5 / 5$

Poverty Score $=[($ Illiteracy Score $)+($ Unemployment Score $)+(2 \times$ Income Score $)] / 4$

Hazard score for socioeconomic drought $=[($ Poverty Score $)+($ Population Annual Growth Rate Score $)+$ (Dependency per capita to each person Score)]/3

Hazard score for non meteorological drought $=[($ hydrological drought Score $)+($ physical drought Score $)+$ (socioeconomic drought Score)]/3

Final of the hazard score for drought $=[($ meteorological drought Score $)+($ non meteorological drought Score)]/2

The hazard score in each polygon denotes the cumulative effect of all the indicators for qualifying the four severity classes (Table 2). This facilitated the production of Figure 2 that showed the different degrees of 
Table 1. Indicators used in the GIS model of drought hazard assessment.

\begin{tabular}{|c|c|c|c|c|c|}
\hline \multirow{2}{*}{$\begin{array}{l}\text { Main } \\
\text { groups }\end{array}$} & \multirow{2}{*}{ Indicators } & \multicolumn{4}{|c|}{ Drought of class limits and their score } \\
\hline & & Slight (1) & Moderate (2) & Severe (3) & Very severe (4) \\
\hline \multirow{7}{*}{ 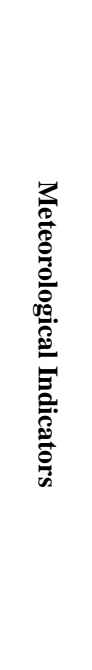 } & $\begin{array}{l}\text { 1) Drought Hazard (Number of } \\
\text { sequential years using WMO definition)* }\end{array}$ & $0-1$ & $2-3$ & $4-5$ & $\geq 6$ \\
\hline & 2) Climate & $\begin{array}{l}\text { Sub humid and } \\
\text { humid }\end{array}$ & Mediterranean & Semi arid & Arid and Very arid \\
\hline & 3) Annual rainfall, mm & $\geq 500$ & $250-499$ & $100-249$ & $<100$ \\
\hline & $\begin{array}{l}\text { 4) Climate Change (significant change } \\
\text { in annual temperature trend during } 100 \\
\text { years and significant change in } \\
\text { climatic index trend) }\end{array}$ & $\begin{array}{l}\text { No change or } \\
<1 \mathrm{C} \text { increase in } \\
\text { temperature }\end{array}$ & $\begin{array}{l}\text { between } 1 \text { - } 4 \mathrm{C} \text { increase } \\
\text { in temperature }\end{array}$ & $\begin{array}{l}>4 \mathrm{C} \text { increase in } \\
\text { temperature or } \\
\text { change in } \\
\text { climatic index }\end{array}$ & $\begin{array}{l}>4 \mathrm{C} \text { increase in } \\
\text { temperature and } \\
\text { change in } \\
\text { climatic index }\end{array}$ \\
\hline & $\begin{array}{l}\text { 5) Coefficient variation }(\mathrm{CV}) \text { of } \\
\text { annual rainfall }\end{array}$ & $<20$ & $20-29$ & $30-39$ & $\geq 40$ \\
\hline & $\begin{array}{l}\text { 6) Ratio (the number of arid years in } \\
\text { station using }(\text { SPI }<-1) \text { to the number } \\
\text { of total years in station }{ }^{* * * * *}\end{array}$ & $<12$ & $12-19.99$ & $20-23.99$ & $\geq 24$ \\
\hline & $\begin{array}{l}\text { 7) Ratio (the number of vernal arid years } \\
\text { in station using (SPI < -1) to the number } \\
\text { of total years in station) }\end{array}$ & $<9.99$ & $10-19.99$ & $20-24.99$ & $\geq 25$ \\
\hline \multirow{4}{*}{ 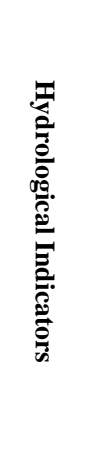 } & 8) Over exploitation of plans $s^{* * * * *}$ & $\geq 1$ & $0.9-0.99$ & $0.8-0.9$ & $<0.8$ \\
\hline & 9) Hydrogeology of plains & $\begin{array}{c}\text { Coarse or Medium } \\
\text { to coarse-grained } \\
\text { texture, very thick } \\
\text { or thick alluvium, } \\
\text { deep water table, } \\
\text { excellent or good } \\
\text { discharge }\end{array}$ & $\begin{array}{l}\text { Relatively fine-grained } \\
\text { texture, moderately } \\
\text { thick alluvium, shallow } \\
\text { water table, medium } \\
\text { discharge }\end{array}$ & $\begin{array}{c}\text { Fine-grained } \\
\text { texture, thin } \\
\text { alluvium, shallow } \\
\text { water table, poor } \\
\text { discharge }\end{array}$ & $\begin{array}{l}\text { Fine to very } \\
\text { fine-grained texture, } \\
\text { very thin alluvium, } \\
\text { shallow water table } \\
\text { or no aquifer, very } \\
\text { poor discharge }\end{array}$ \\
\hline & $\begin{array}{l}\text { 10) Stream density in each } \\
\text { hydrogeological unit }\left(\mathrm{km} / \mathrm{km}^{2}\right)^{* * * * * * * *}\end{array}$ & $<0.3$ & $0.3-0.59$ & $0.6-0.89$ & $\geq 0.9$ \\
\hline & $\begin{array}{l}\text { 11) Annual average decrease of } \\
\text { watertable in each plan (m/year) }\end{array}$ & $<0.05$ & $0.05-0.79$ & $0.8-1.49$ & $\geq 1.5$ \\
\hline \multirow{5}{*}{ 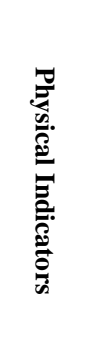 } & 12) Derange condition of soil & Very good, Good & Suitable, moderate & poorly & unsuitable \\
\hline & 13) Slop (\%) & $<2$ & $16.99-2$ & $29.99-17$ & $>30$ \\
\hline & 14) Land use & Rock, Bare land & $\begin{array}{l}\text { Forest, irrigation } \\
\text { cultivation }\end{array}$ & Range land & Dry cultivation \\
\hline & $\begin{array}{l}\text { 15) Ratio (dry cultivation area to } \\
\text { irrigation area) in each plan (\%) }\end{array}$ & $<0.3$ & $0.3-0.599$ & $0.6-0.9$ & $>0.9$ \\
\hline & $\begin{array}{l}\text { 16) Water dependency per capita } \\
\text { to irrigated area (cube meter per } \\
\text { year per hectare) }\end{array}$ & $\geq 30,000$ & $30,000-18,000$ & $18,000-6000$ & $<6000$ \\
\hline \multirow{5}{*}{ 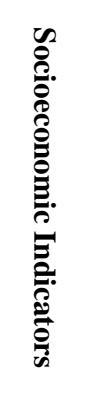 } & $\begin{array}{l}\text { 17) Income from } \\
\text { agriculture (amount of } \\
\$ \text { per person per year) }\end{array}$ & $\geq 650$ & $649.9-400$ & $399.9-100$ & $<100$ \\
\hline & 18) Illiteracy (\%) & $<7$ & $19.9-7$ & $19.9-34.9$ & $\geq 35$ \\
\hline & 19) Unemployment (\%) & $<5$ & $5-14.99$ & $15-24.99$ & $\geq 25$ \\
\hline & $\begin{array}{l}\text { 20) Water dependency per capita to } \\
\text { each person (cube meter per year } \\
\text { per person) }\end{array}$ & $\geq 7000$ & $7000-4000$ & $4000-1000$ & $<1000$ \\
\hline & $\begin{array}{l}\text { 21) Population Annual Growth } \\
\text { Rate (\%) }\end{array}$ & $\leq 1.49$ & $1.5-2.49$ & $2.5-3.49$ & $\geq 3.5$ \\
\hline
\end{tabular}

Note: *Drought year is when rainfall is less than $60 \%$ of normal and continues two years, ${ }^{* *}$ Climatic index: De Martonne index for this research, $\mathrm{I}=$ $\mathrm{P} /(\mathrm{T}+10),{ }^{* * *} \mathrm{CV}=($ Standard deviation of rainfall/Average rainfall $) \times 100,{ }^{* * * *} \mathrm{SPI}=($ total rainfall in a year - average of annual rainfall $) /$ standard deviation of period, ${ }^{* * * * *}$ Over exploitation = Safe exploitation $\left(\mathrm{Mm}^{3}\right) /$ actual extraction $\left(\mathrm{Mm}^{3}\right) \mathrm{Mm}^{3}$ : Million cube meter, ${ }^{* * * * * *}$ Stream density: length of washes and rivers in each unit $(\mathrm{km}) /$ area of unit $\left(\mathrm{km}^{2}\right)$. 
Table 2. The severity classes of hazard map produced in the GIS.

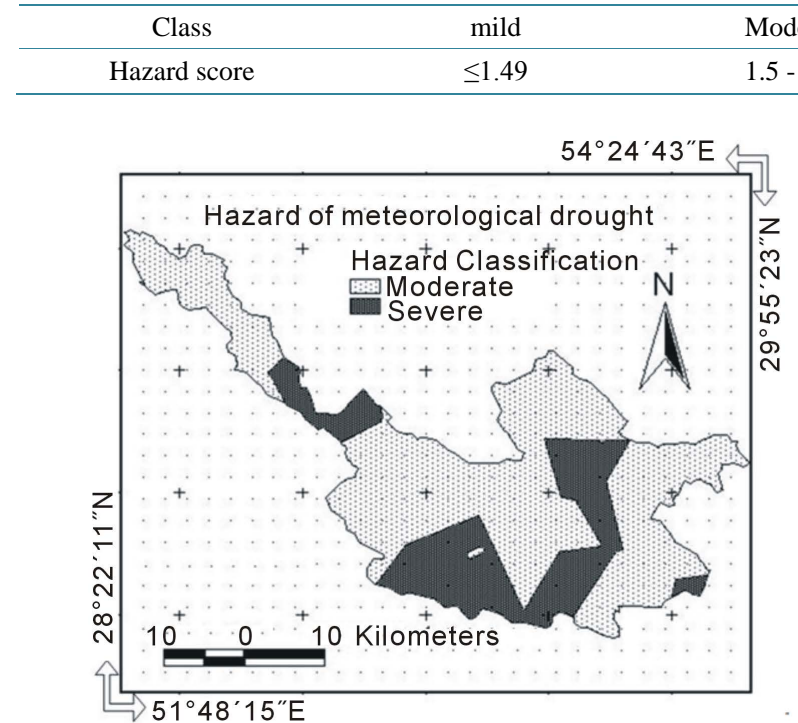

(a)

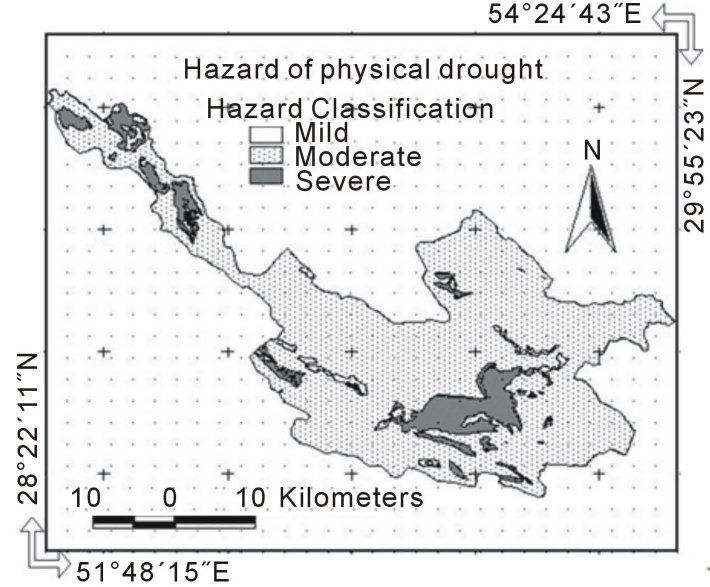

(c)

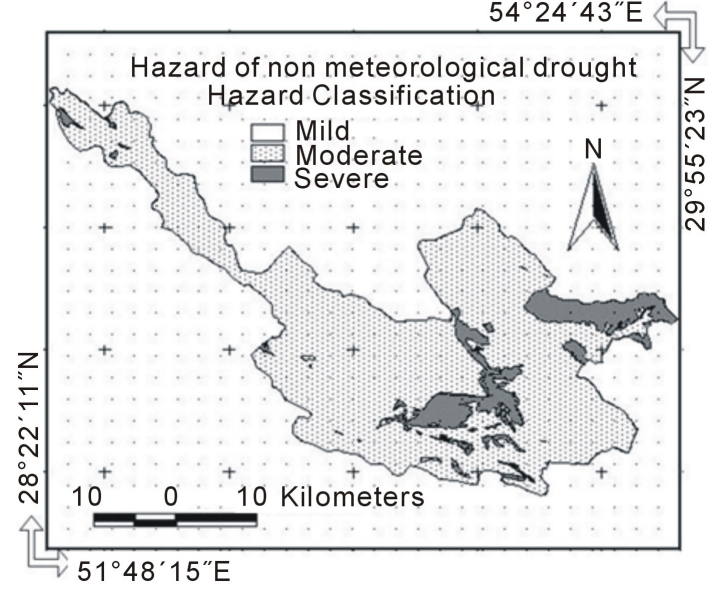

(e)

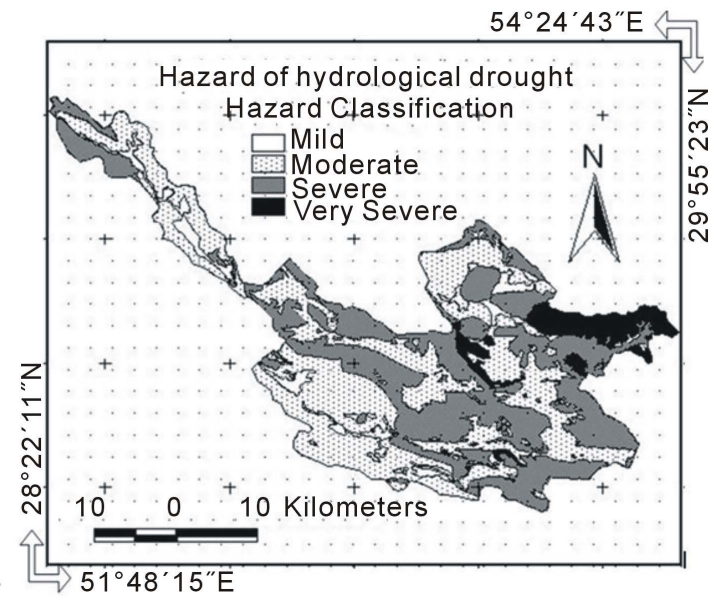

(b)

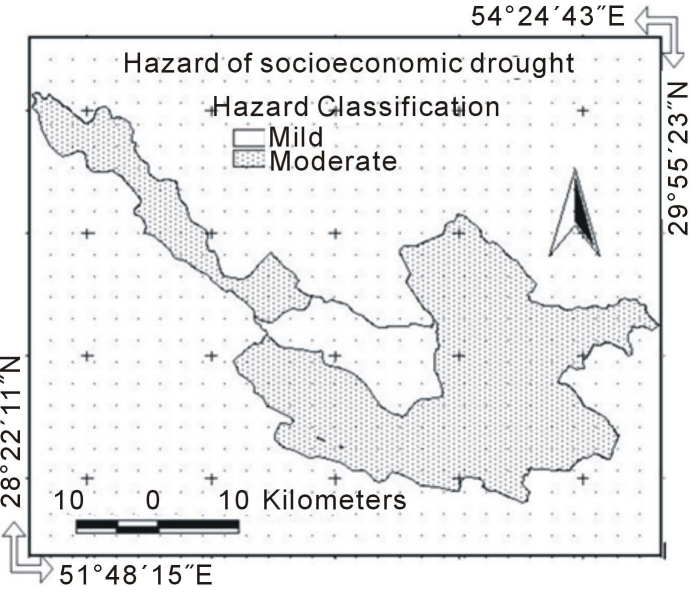

(d)

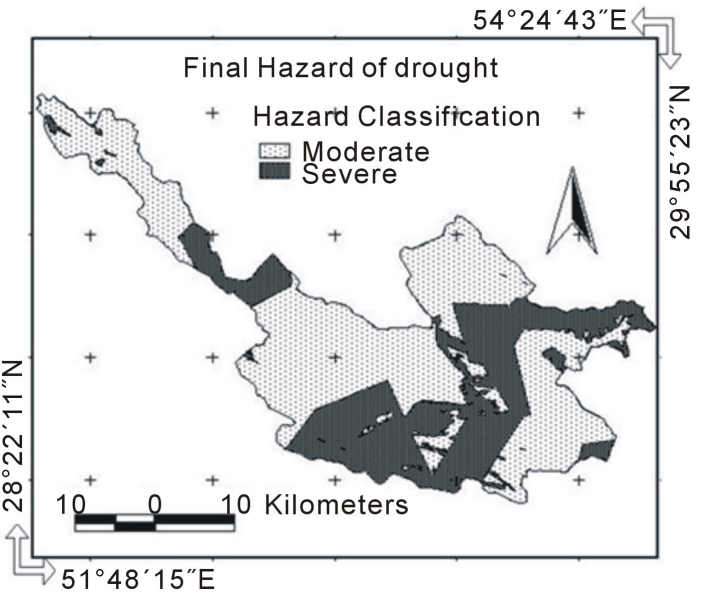

(f)

Figure 2. (a) Hazard of meteorological drought; (b) Hazard of hydrological drought; (c) Hazard of physical drought; (d) Hazard of socioeconomic drought; (e) Hazard of non meteorological drought; (f) FinalHazard of drought. 
drought Hazard.

\section{Results and Discussion}

Most studies so far done in Iran like Masoudi [9] and in the world have based their estimation on the "present state" of drought hazard. The drought hazard maps or information alone based on the present state of hazard derived that shown those areas which are more vulnerable to the hazard. It requires a combination of all causes of hazard like different human activities, natural cause and the data showing current state of hazard. The present model finds the severity of ground water resource degradation using cumulative effect of all indicators based on DPSIR framework. This kind of classification using different indicators which some of them have not been used in other literatures for such studies is the first attempt of its kind for defining areas with higher hazard of drought. The GIS analysis not only facilitated the model those development but also allowed the evaluation of spatial correlation and hazard map production. The hazard map of the GharehAghaj basin (Figure 2) shows different hazard classes.

The results of this study show that:

\subsection{Hazard of Meteorological Drought}

Figure 2(a) and Table 3 show that the areas under mild class of hazard of meteorological drought cover about $0 \%$ of the total basin, areas under moderate class is about $63 \%$, areas under severe class is about $37 \%$ and areas under very severe class is about $0 \%$ of the total basin.

\subsection{Hazard of Hydrological Drought}

Figure 2(b) and Table 3 show that the areas under mild class of hazard of hydrological drought cover about 5\% of the total basin , areas under moderate class is about $46 \%$, areas under severe class is about $42 \%$ and areas under very severe class is about $7 \%$ of the total basin.

\subsection{Hazard of Physical Drought}

Figure 2(c) and Table 3 show that the areas under mild class of hazard of physical drought cover about $1 \%$ of the total basin , areas under moderate class is about $89 \%$, areas under severe class is about $10 \%$ and areas under very severe class is about $0 \%$ of the total basin.

\subsection{Hazard of Socioeconomic Drought}

Figure 2(d) and Table 3 show that the areas under mild class of hazard of socioeconomic drought cover about $14 \%$ of the total basin, areas under moderate class is about $86 \%$, areas under severe class is about $0 \%$ and areas under very severe class is about $0 \%$ of the total basin.

\subsection{Hazard of Non Meteorological Drought}

Figure 2(e) and Table 3 show that the areas under mild class of hazard of non meteorological drought cover about $0.2 \%$ of the total basin, areas under moderate class is about $88.17 \%$, areas under severe class is about

Table 3. Areas under hazard classes.

\begin{tabular}{|c|c|c|c|c|c|}
\hline \multirow{2}{*}{ Hazard type } & \multicolumn{5}{|c|}{ Geographical extent (in \%) for the hazard classes } \\
\hline & Mild & moderate & Severe & Very severe & Total \\
\hline Hazard of meteorological drought & $0 \%$ & $63 \%$ & $37 \%$ & $0 \%$ & $100 \%$ \\
\hline Hazard of hydrological drought & $5 \%$ & $46 \%$ & $42 \%$ & $7 \%$ & $100 \%$ \\
\hline Hazard of physical drought & $1 \%$ & $89 \%$ & $10 \%$ & $0 \%$ & $100 \%$ \\
\hline Hazard of socioeconomic drought & $14 \%$ & $86 \%$ & $0 \%$ & $0 \%$ & $100 \%$ \\
\hline Hazard of non meteorological drought & $0.2 \%$ & $88.17 \%$ & $11.63 \%$ & $0 \%$ & $100 \%$ \\
\hline Final Hazard of drought & $0 \%$ & $89.87 \%$ & $10.13 \%$ & $0 \%$ & $100 \%$ \\
\hline
\end{tabular}

Note: Total area of basin is $12,649 \mathrm{~km}^{2}$. 
$11.63 \%$ and areas under very severe class is about $0 \%$ of the total basin.

\subsection{Hazard of Drought in the GharehAghaj Basin}

From the Figure 2(f) and Table 3 a general conclusion can be derived that in the plains of GharehAghaj basin the moderate drought hazard area cover mainly surface of the region. Almost the severe drought hazard area covers approximately $10.13 \%$ of the regain.

\section{Conclusions}

Preparation of a Hazard Map is seen as a prerequisite for planning agricultural and environmental conservation. The GharehAghaj basin model is the first attempt of its kind for defining the real hazard of drought and can be made applicable for other areas in Iran and elsewhere. This model has been applied for a regional scale but if the data of indicators for smaller scales are available, it can be used also to measure hazard for smaller areas. The main results of the present paper are:

1) The hazard maps of twenty one indicators give a far better opportunity to distinguish the severity classes of hazard of drought. This kind of map shows areas under different classes of vulnerability and risk of drought and differs from those maps showing current state of hazard.

2) The final map of drought hazard shows that both severe and moderate hazardous areas it is concluded that the areas under severe hazard cover about $10.13 \%$ of the total basin, while those under moderate hazard have a greater spread (89.87\%), but area under mild and very severe hazard is $0 \%$ of the basin are awhile the mild hazardous areas by use of meteorological, hydrological, physical, socioeconomic and non meteorological drought sequence were $0,5 \%, 1 \%, 14 \%$ and $0.2 \%$. Moderate hazardous areas by use of meteorological, hydrological, physical, socioeconomic and non meteorological drought sequence were 63\%, 46\%, 89\%, 86\% and 88.17\%. Severe hazardous areas by use of meteorological, hydrological, physical, socioeconomic and non meteorological drought sequence were 37\%, 42\%, 10\%, 0\% and 11.63\%. Very severe hazardous areas by use of meteorological, hydrological, physical, socioeconomic and non meteorological drought sequence were $0 \%, 7 \%, 0 \%, 0 \%$ and $0 \%$. Obtained result showed that in major type of drought hazard, areas under moderate and severe hazardous classes are at the most mount.

3) The remedial measures should be undertaken by selecting the priority areas. Areas under severe hazard (indicated in the hazard map) will be the areas needing immediate and the sensitive areas (the areas under severe classes) are spread mostly in south, central and north east of basin therefore these areas are prior for managements and controlling activity.

\section{Acknowledgements}

The authors are thankful to the Government Offices of Iran, for providing the data, maps and reports for this hazard assessment work.

\section{References}

[1] Ahmadi, H. (1995) Applied Geomorphology Book. Tehran University Publication, Tehran, 613 p.

[2] Ahmadi, H., Abbas Abadi, M.R., Onagh, M. and Ekhtessasi, M.R. (2001) Quantitative Assessment of Desertification in Aghqalla and Gomishan Plain for Creation of a Regional Model. Iranian J. Natural Resources, 54, 3-22.

[3] Anukularmphai, A., Shabiruzzaman and Ullah. E. (1990) Rainfall and Evaporation Analysis of Thailand. Division of Agricultural and Food Engineering, The Asian Institute of Technology, Bangkok. http://gecnet.kku.ac.th/.../n.../1_Spatial\%20and\%20Temporal\%20Analysis.pdf

[4] DEPP (1996) Flood and Natural Risk Area in Northeast Thailand Project Bangkok. Ministry of Science, Technology and Environment. http://edl.envr.tsukuba.ac.jp/jp/common/pdf/2011_mongolia_sympo.pdf

[5] Feiznia, S., Gooya, A.N., Ahmadi, H. and Azarnivand, H. (2001) Investigation on Desertification Factors in HosseinAbad Mish Mast Plain and a Proposal for a Regional Model. Journal of Biaban, 6, 1-14. http://www.noormags.com/view/fa/articlepage/443946

[6] Grunblatt, J., Ottichilo, W.K. and Sinange, R.K. (1992) A GIS Approach to Desertification Assessment and Mapping. Journal of Arid Environments, 23, 81-102. http://books.google.com/books?isbn=9171063579

[7] Koonthanakulwong, S. (1990) Meteorological Drought in Northeast Thailand. Chulalongkorn University, Bangkok. 
http://gecnet.kku.ac.th/research/i_proceed/.../3_Drought\%20Assessment.pdf

[8] Kumar, S. (1992) Assessment of Vegetation Degradation: Status of Methodological Research. Annals of Arid Zone, 31, 53-62. http://central.oak.go.kr/search/detailarticle.jsp?article_seq=11921

[9] Masoudi, M., Patwardhan, A.M. and Gore, S.D. (2007) Risk Assessment of Lowering of Ground Water Table Using GIS for the QarehAghaj Sub Basin, Southern Iran. Journal of the Geological Society of India, 70, 861-872. http://m.riss.kr/search/detail/DetailView.do?p_mat_type=e21c2016a7c3498b\&control_no=363e9a254c0c97c6ffe0bdc3 ef48d419

[10] NESDB (1992) The Eight National Economic and Social Development Plan. Office of the Prime Minister, Bangkok. http://eng.nesdb.go.th/Default.aspx?tabid=387

[11] Palmer (1965) Meteorological Drought, Office of Climatology. US Weather Bureau, Research Paper No. 45, Washington DC, 58 p. http://www.ncdc.noaa.gov/temp-and-precip/drought/docs/palmer.pdf

[12] Singh, S., Kar, A., Joshi, D.C., Ram, B., Kumar, S., Vats, P.C., Singh, N., Raina, P., Kolarkar, A.S. and Dhir, R.P. (1992) Desertification Mapping in Western Rajasthan. Annals of Arid Zone, 31, 237-246. http://books.google.com/books?isbn=8125027351

[13] Siripon, K. and Mongkolsawat, C. (2000) Spatial and Temporal Analysis of Rainfall Pattern in Northeastern Thailand: Application of GIS. Journal of Remote Sensing and GIS, Association of Thailand, 1, 1-18. http://gecnet.kku.ac.th/research/i_proceed/2550/1_Estimation_of_rainfall.pdf

[14] Zareiee, A.R. and Masoudi, M. (2011) Assessment of Meteorological Drought Hazard Area using GIS in GharehAghaj basin, Iran. Journal of Applied Science and Environmental Management, 15. http://www.ajol.info/index.php/jasem/article/view/65670

[15] Zehtabian, G. and Jafari, R. (2002) Evaluation of Water Resources Degradation in Kashan Area Using Desertification Model. Journal of Ecology, 30, 19-30. http://jes.ut.ac.ir/?_action=articleInfo\&article=11016\&vol=1104 